Monika Spychalska-Wojtkiewicz

Uniwersytet Szczeciński

e-mail: monika.wojtkiewicz@wzieu.pl

\title{
Rola modelu ZMOT w zarządzaniu w podmiotach kultury
}

Abstract

\section{The Role of the ZMOT Model in the Management of Cultural Entities}

This article deals with Google's ZMOT model and its potential use in cultural entities. The article analyses the application of the model, using one particular culture unit as a study case.

Keywords: ZMOT model, relationship management, client, cultural entities.

Słowa kluczowe: model ZMOT, zarządzanie relacjami, klient, podmioty kultury.

\section{Wprowadzenie}

Podmioty kultury stanowią specyficzne jednostki, do których przetransferowanie rozwiązań z powodzeniem stosowanych w przedsiębiorstwach komercyjnych nie zawsze jest możliwe. Niemiej jednak, o ile rynek podmiotów kultury jest specyficzny, o tyle podlega on takim samym mechanizmom, jak inne rynki. Dla podmiotów działających w sferze kultury trendy nie powinny stanowić trudności, jedynie arenę do wykorzystania ich kreatywnego potencjału. Bardzo często jest jednak inaczej i aktualne trendy rynkowe niosą głównie trudne wyzwania, które częściej przeradzają się w istotne problemy niż w szanse na rozwój. 


\section{Specyfika podmiotów kultury w kontekśscie sektorów kreatywnych}

Zauważa się, że pojęcie „sektora kultury” bardzo się upowszechniło, przez co często bywa używane w różnych zakresach znaczeniowych, od ujęcia szerokiego, jako zbiór wszelkich podmiotów kultury: instytucji kultury, szkół artystycznych, organizacji pozarządowych, przedsiębiorstw prywatnych, po zawężone, jako zbiór podmiotów reprezentujących przemysły kultury czy przemysły kreatywne ${ }^{1}$. Tym samym należy zauważyć, iż w Polsce podmioty zajmujące się działalnością kulturalną tworzą szeroki krąg instytucji publicznych, organizacji pozarządowych i prywatnych, takich jak np.:

- teatry;

- opery;

- operetki;

- filharmonie;

- orkiestry;

- instytucje filmowe;

- kina;

- muzea;

- biblioteki;

- domy kultury;

- ogniska artystyczne;

- galerie sztuki;

- ośrodki badań i dokumentacji w różnych dziedzinach kultury;

- szkoły i uczelnie artystyczne.

Działalność kulturalną mogą prowadzić zarówno osoby prawne (np. instytucje kultury, stowarzyszenia, fundacje, spółki prawa handlowego, uczelnie publiczne i niepubliczne), jak i osoby fizyczne oraz jednostki organizacyjne nieposiadające osobowości prawnej (np. część szkół, domy pomocy społecznej, urzędy). Podmioty, których podstawowym celem jest prowadzenie działalności kulturalnej, są określane mianem instytucji kultury. W tym kontekście należy wziąć również pod uwagę sektor kreatywny, który z kulturą jest w znaczący sposób związany².

Szczególnie pojęcie twórczości i kreatywności łączy podmioty kultury oraz sektora kreatywnego. Sama kreatywność może być analizowana również w ujęciu sztuki, odnosząc się do umiejętności tworzenia czegoś nowego. David Throsby zdefiniował ją jako wyobraźnię pochodzącą z istniejących, nowych i łączonych

${ }^{1}$ http://badania-w-kulturze.mik.krakow.pl/2012/02/22/sektor-kultury-ujecie-instytucjonalne-i-znaczenie-gospodarcze/ (data dostępu: 20.08.2017).

${ }^{2}$ Podręcznik szkoleniowy dotyczący sektora kultury w Polsce dla wnioskodawców i partnerów programu Promowanie różnorodności kulturowej i artystycznej $w$ ramach europejskiego dziedzictwa kulturowego finansowanego z funduszy EOG 2009-2014, Ministerstwo Kultury i Dziedzictwa Narodowego, Warszawa 2012, s. 5 . 
pomysłów, ocenę, która reguluje i kontroluje wyobraźnię oraz smak określany jako wewnętrzne odczucie ${ }^{3}$.

W ekonomii kreatywność określana jest głównie poprzez związane z nią innowacje. W teorii Josepha Aloisa Schumpetera kreatywność rozumiana jest w ramach innowacji jako dynamiczny proces wewnątrzekonomiczny. Schumpeter nie określał jednak pojęcia kreatywności jako tworzenia nowych rzeczy w sztuce, ale jako oryginalność w wyrażaniu, która jest osiągana dzięki rozwojowi edukacji, inwestycjom, pracy nad strukturami przedsiębiorstw oraz zarządzaniem personelem ${ }^{4}$.

Istotny nacisk na innowacyjność podmiotów gospodarczych sprawił, iż szczególną uwagę zaczęto zwracać na podmioty z natury swojej działalności nakierowane na twórczą działalność oraz kreatywność.

Sektor kreatywny na świecie i w Europie bywa definiowany odmiennie, co również wynika z szerokiego zakresu, jaki obejmuje. W Stanach Zjednoczonych nazywa się go na przykład przemysłem informacyjnym, podczas gdy w Niemczech określa się go jako gospodarkę kultury ${ }^{5}$. W Polsce przyjęto, by termin creative industries tłumaczyć jako „sektory kreatywne” lub „przemysły kreatywne” oraz opierać na brytyjskiej definicji, głoszącej, iż są to przemysły, które mają źródło w indywidualnej kreatywności, umiejętnościach oraz talencie i które wykazują potencjał do tworzenia dobrobytu i miejsc pracy poprzez generowanie i wykorzystywanie własności intelektualnej'.

Analizując sektory kreatywne szeroko, należy je rozumieć jako kreatywne przedsiębiorstwa, które w szczególności zorientowane są na rynek, zajmują się kreacją, produkcją, dystrybucją, rozprzestrzenianiem kreatywnych dóbr i usług, w tym poprzez media ${ }^{7}$. Sektor kreatywny swoim zakresem obejmuje w istotny sposób obszary związane z kulturą:

- główne dziedziny kultury (działania nieprzemysłowe), czyli wytwarzanie niereprodukowalnych dóbr i usług;

- przemysły bezpośrednio związane z kulturą, czyli działania mające na celu wytwarzanie dóbr i usług kulturalnych na skalę masową, (np. produkcja audiowizualna, gry wideo, radiofonia i telewizja),

- przemysły kreatywne pośrednio związane z kulturą, na które składają się przedsięwzięcia, w których kultura staje się „kreatywnym” wkładem (np. projektowanie, wzornictwo przemysłowe, reklama).

${ }^{3}$ EC, Economy of Culture in Europe, DG Education and Culture, Bruksela 2006, s. 41.

4 Tamże, s. 41.

${ }^{5}$ M. Koszarek, Diagnoza Sektora branż kreatywnych na obszarze Metropolii Gdańskiej, raport końcowy, s. 11.

${ }^{6} \mathrm{http}: / /$ kreatywnapolska.pl/klasyfikacja-przemyslow-kreatywnych (data dostępu: 20.08.2017).

7 M. Mackiewicz, B. Machorowska, A. Śliwka, Analiza potrzeb i rozwoju sektorów kreatywnych raport końcowy, Warszawa 2009, http://www.mg.gov.pl/files/upload/10147/Analiza\%20potrzeb\%20 i\%20rozwoju\%20przemyslow\%20kreatywnych.pdf (data dostępu: 20.08.2017). 
W przypadku zarówno podmiotów kultury, jak sektorów kreatywnych twórczość jest głównym czynnikiem procesu produkcji, natomiast własność intelektualna stanowi charakterystyczną cechę rezultatu. Nie tylko obszary obejmujące sektor kreatywny wskazują na jego powiązanie z podmiotami kultury. Europejski Urząd Statystyczny (European Statistical Office - EUROSTAT) również opracował definicję sektora kreatywnego, w której skupił się na określeniu go poprzez działania w sektorze kultury związane z zachowaniem, twórczością, produkcją, rozpowszechnianiem, handlem oraz edukacją we wszystkich dobrach i usługach kulturalnych w następujących sferach':

- dziedzictwo kulturowe - pomniki historii, muzea, stanowiska archeologiczne, inne dziedzictwo;

- książki i prasa, na przykład książki, gazety i czasopisma;

- sztuki wizualne, na przykład design, fotografia;

- architektura;

- archiwa;

- biblioteki;

- sztuki performatywne, na przykład muzyka, taniec, teatr;

- media audio i audiowizualne/multimedia, na przykład film, radio, telewizja, wideo.

Tym samym można zauważyć, jak bardzo powiązane są z sobą specyfika i zakres działalności podmiotów kultury oraz sektora kreatywnego. Niemniej jednak specyfika podmiotów sektora kreatywnego osadza je głęboko w kontekście konkurencyjnego rynku. Tym samym przedsiębiorstwa te swoją kreatywność wykorzystują na rzecz wzbogacania produktów, usług, designu czy też wdrażania innowacji, podczas gdy podmioty kultury nie zawsze postępują w ten sposób.

W przypadku podmiotów kultury, ze względu na ich charakter działalności, trudno jest również zaobserwować postawy proinnowacyjne, świadome zarządzanie relacjami rynkowymi czy też zarządzanie podmiotem w myśl zasad zarzadzania projektowego lub procesowego. Wpływ na ten aspekt może mieć głównie specyfika nietechnologiczna w zakresie prowadzonych działań, co automatycznie przekłada się na niższy poziom wdrażania innowacji czy też fakt, iż są to bardzo często niewielkie podmioty działające w myśl pewnych schematów postępowania.

W przypadku przedsiębiorstw sektora MSP zauważa się, iż realizacja przedsięwzięć określonych w czasie, mających wyznaczony budżet i cel pozwala menedżerom w bardziej świadomy i strategiczny sposób zarząadzać podmiotem. Tym samym zarządzanie projektowe może się przełożyć na wdrożenie w przedsiębiorstwie kompleksowego podejścia do zarząazania firma, podobnie jak na przykład model ZMOT na zarządzanie relacjami z klientami.

${ }^{8}$ A. Etmanowicz, M. Trzebański, B. Martele, Rekomendacje działań i kierunków wsparcia rozwoju przemysłów kreatywnych w województwie pomorskim, Toruń 2012, http://kreatywni.arp.gda.pl/ plik,57,rekomendacje-dzialan-i-kierunkow-wsparcia-przemyslow-kreatywnych-w-wojewodztwie-pomorskim.pdf (data dostępu: 20.08.2017). 


\section{Model ZV0T w zarządzaniu relacjami $z$ klientem}

Relacje z klientami są głównym stymulatorem rozwoju organizacji. To właśnie klienci decydują o istnieniu danego podmiotu. Jeśli klientów ubywa, organizacja traci sens swojego bytu. Uzasadnianie biznesowe znane z terminologii metody zarządzania projektami Prince2 również wskazuje na ważność opisu przyczyn przedsięwzięcia organizacyjnego, opartego na oszacowanych kosztach projektu związanych z nim ryzykiem oraz spodziewanych korzyściach dla klienta, służąc do ciągłego potwierdzania sensowności kontynuacji działań .

Ostatnia dekada to okres znacznych zmian w sytuacji rynkowej w różnych branżach, których siłami sprawczymi są głównie narastająca konkurencja, globalizacja gospodarki, wzrastające oczekiwania klienta wynikające z coraz większej świadomości oraz nowe technologie ${ }^{10}$. Podmioty kultury z pewnością są świadome tych zmian, gdyż są one ogólnie odczuwalne oraz przekładają się na wymagania wobec nich samych. Niemniej jednak, o ile pewne podmioty sektora kreatywnego świadomie wpisują się w panujące trendy, o tyle podmioty kultury nie zawsze potrafią sobie z nimi poradzić. Jest to jednak szczególnie ważne, gdyż podmioty stają przed szeregiem coraz to nowszych wyzwań, które opisał między innymi Gordon Mathews w książce zatytułowanej Supermarket kultury ${ }^{11}$. Pozycja ta obnaża specyficzny rodzaj konsumenta kultury oraz model jego w niej uczestnictwa. Obecnie klient kultury może wybierać wśród ogromnej oferty dóbr i usług kultury, jednocześnie bardzo zróżnicowanej i pochodzącej od szeregu dostawców, w tym nie tylko znajdujących się $\mathrm{w}$ regionie zamieszkania odbiorcy.

Nowoczesny klient - obiorca oferty podmiotów kultury może być dla nich jednocześnie ogromnym wyzwaniem. Nie bez znaczenia dla tego faktu pozostają wzrost znaczenia technologii ICT (information and communication technologies) oraz ogólna dostępność internetu. Możliwość ciągłego poszerzania kontaktów z kulturą przez internet jest niezwykle istotna, ale uzyskuje dodatkowy wymiar wówczas, gdy odbiorca kultury chce się z nią skonfrontować osobiście i fizycznie skorzystać z oferty podmiotów kultury. W tym wypadku przedstawiciele tychże podmiotów powinni mieć w zanadrzu opracowaną politykę zarządzania klientami polegającą między innymi na opracowaniu:

- koncepcji zdobycia oraz zatrzymania klienta;

- budowania zadowolenia klienta;

- identyfikacji miejsc styku z klientem (tzw. touch points).

W kontekście nowoczesnego odbiorcy jest to jednak już zdecydowanie za mało. Naprzeciw tym potrzebom wychodzi model ZMOT (zero moment of truth) opracowany

\footnotetext{
9 OGC: Managing Successful Projects..., s. 15.

${ }^{10}$ D. Buchnowska, CRM strategia i technologia, Gdańsk, 2006, s. 13-14.

${ }^{11}$ G. Mathews, Supermarket kultury. Kultura globalna a tożsamość jednostki, Warszawa 2005, s. 40-42.
} 
przez Google, będący koncepcją marketingową, u podstaw której leży obserwacja o zmianie modelu podejmowania decyzji zakupowych przez konsumentów ${ }^{12}$.

Przede wszystkim model ZMOT wskazuje na znaczące przyspieszenie momentu podjęcia wstępnej decyzji, która dawniej zapadała w miejscu zakupu, a teraz ma miejsce raczej podczas sprawdzania rekomendacji w internecie.

Model ZMOT został zaprezentowany przez Google w publikacji ZMOT - Winning The Zero Moment of Truth oraz poparty szeregiem badań wśród konsumentów. U podstaw modelu pojawiło się kilka twierdzeń dotyczących etapów decyzyjnych i zakupowych klienta.

Dotychczas stwierdzano, iż konsument kierowany bodźcem, na przykład w postaci reklamy, udawał się do punktu sprzedaży (przedsiębiorstwa, organizacji) i dopiero obcując z produktem, podejmował decyzję zakupową. Ten moment określany był jako pierwszy moment prawdy (first moment of truth). W praktyce mógł on oznaczać, iż klient kierowany bodźcem wybierał się do księgarni celem zweryfikowania, czy upatrzona przez niego pozycja książkowa będzie dla niego właściwa. Tak zwany drugi moment prawdy (second moment of truth) następował po zakupie, w toku zbierania doświadczeń użytkownika. Tym samym klient, na przykład czytając książkę po powrocie do domu, wyrabiał sobie opinie o podjętej decyzji.

Model ZMOT (zero moment of truth - zerowego momentu prawdy) zakłada, że decyzja (przynajmniej wstępna) następuje pomiędzy bodźcem a udaniem się po zakup, czyli głównie w internecie, na przykład podczas obcowania z rekomendacjami internautów. Rysunek 1 prezentuje koncepcję modelu ZMOT.

Model ZMOT stanowi narzędzie, które w łatwy sposób może być aplikowane przez przedsiębiorstwa, w tym szczególnie podmioty kultury, co wynika ze specyfiki tychże podmiotów sprawiającej, iż często klient jednocześnie zakupuje usługę świadczoną przez podmiot kultury oraz ją konsumuje. Tym samym klient musi być już zdecydowany co do swojego wyboru, gdyż na przykład nie jest w stanie odseparować zakupu udziału w koncercie od jego konsumpcji. Celem uniknięcia dysonansu pozakupowego klienci kultury często korzystają z różnego rodzaju rekomendacji, które można znaleźć w internecie, lub też audiowizualnych informacji o danym wydarzeniu kulturalnym, tak by zapoznać się z nim wcześniej i dokonać ostatecznego zakupu. Oznacza to właśnie, iż klienci podmiotów kultury podejmują decyzję o zakupie zdecydowanie wcześniej niż pojawią się w miejscu świadczenia i robią to między innymi, poszukując informacji w internecie.

12 https://www.thinkwithgoogle.com/marketing-resources/micro-moments/zero-moment-truth/ (data dostępu: 17.08.2017). 


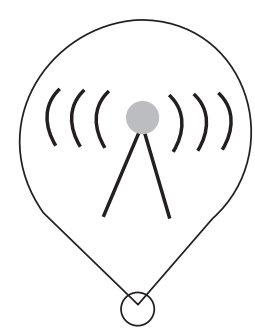

bodziec

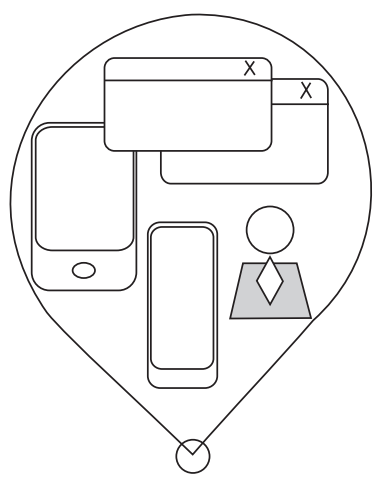

ZMOT zerowy moment prawdy (zero moment of truth)

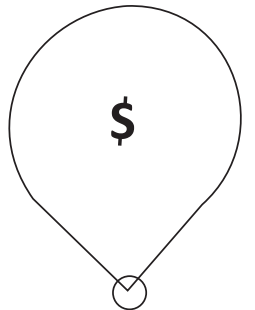

FMOT

pierwszy moment prawdy (first moment of truth)

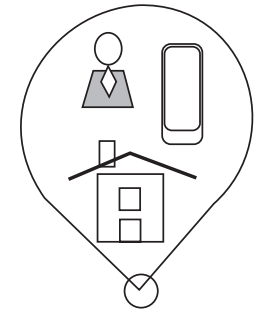

SMOT drugi moment prawdy (second moment of truth)

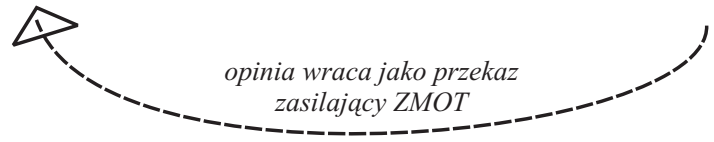

Rysunek 1. Model zerowego momentu prawdy - ZMOT

Źródło: opracowanie własne na podstawie https://www.thinkwithgoogle.com/marketing-resources/micro-moments/zero-moment-truth/ (data dostępu: 15.08.2017).

Aspekt ten przekłada się na szereg rekomendacji dla podmiotów kultury w zakresie zarządzania relacjami z klientami, takich jak na przykład:

- wyznaczenie punktów styku podmiotu oraz klientów (touch points);

- obecność informacji o organizacji, ofercie organizacji w miejscach styku (w miejscach, gdzie są odbiorcy);

- dbałość o informacje na temat danego podmiotu zamieszczone w internecie, na różnego rodzaju platformach, na przykład stronie www, ale i w mediach społecznościowych, na forach, portalach regionalnych i branżowych;

- wyznaczenie, z jakich urządzeń klienci korzystają, oraz dostosowanie się do ich wymogów technicznych, na przykład do wymogów urządzeń mobilnych czy też aplikacji;

- dbałość o pozycjonowanie informacji w wyszukiwarkach internetowych;

- określnie słów kluczowych, według których klienci mogą wyszukiwać informacje;

- określenie, czego mogą szukać klienci, jakie mogą mieć pytania, jakich informacji może im brakować;

- tworzenie treści, która może być pomocna klientowi wg modelu ZMOT (treści różnego rodzaju: opisów, filmów, audio).

Przedsiębiorcy mają już wiadomość, że posiadanie strony www jest konieczne by dysponować własną wizytówką w przestrzeni wirtualnej, niemniej jednak nie wszystkie podmioty kultury mają tę świadomość, co więcej - owa świadomość jako 
podstawa działalności już nie wystarczy. Ważne jest w kontekście modelu ZMOT całościowe myślenie o informacjach, które pojawiają się w internecie. Jest to o tyle ważne, że rolę sprzedażową w znaczącej mierze przejmują rekomendacje, oceny i informacje znalezione przez konsumentów w internecie.

Google poparło model ZMOT badaniami, które wskazują między innymi, że ${ }^{13}$ :

- $37 \%$ badanych przyznało, że znalezione w internecie recenzje mają istotny wpływ na ich decyzje konsumenckie;

- $84 \%$ badanych używa internetu do szukania informacji o produktach, które chcą kupić;

- $54 \%$ porównuje produkty przy użyciu internetu;

- $62 \%$ badanych szuka w internecie promocji, zanim podejmie decyzję o zakupie produktu w pełnej cenie;

- internauci częściej stykają się z pozytywnymi recenzjami produktów (pozytywne komentarze zamieszczane są częściej);

- największe znaczenie mają rekomendacje znajomych, treść na profilach społecznościowych podmiotu oraz blogi konsumenckie.

W celu najpełniejszego wykorzystania modelu ZMOT zaleca się wyznaczenie pracownika odpowiedzialnego za komunikację z klientami, w tym komunikację przez internet, oraz określenie punktu ZMOT w danym podmiocie. Następnie możliwe jest już przystąpienie do działania, gdyż ZMOT nie wymaga rozbudowanych strategii, a jedynie świadomego sterowania informacją, tak by była ona maksymalnie użyteczna z punktu widzenia klienta.

\section{Lastosowanie modelu ZMOT na przykladzie Szczecińskiego Inkubatora Kultury}

Szczeciński Inkubator Kultury (INKU) stanowi podmiot, który zaliczyć można zarówno do grupy podmiotów kultury, jak i podmiotów sektora kreatywnego. Powstał 1 września 2011 roku. Powołany przez Miasto Szczecin od momentu powstania ma być odpowiedzią na potrzeby organizacji operujących w trzecim sektorze w obszarze kultury. Inkubator działa na rzecz organizacji pozarządowych, które dopiero wstępują na ścieżkę rozwijania społeczeństwa obywatelskiego ${ }^{14}$.

Model działań INKU jest dość szeroki, organizacja oferuje:

- pomoc zarówno początkującym podmiotom, na przykład w zakresie zakładania stowarzyszenia, jak i od niedawna aktywnym na arenie sektora pozarządowego;

- wynajem powierzchni biurowych i użytkowych po preferencyjnych stawkach;

${ }^{13} \mathrm{~N}=5000$ internautów, https://www.thinkwithgoogle.com/marketing-resources/micro-moments/zero-moment-truth/ (data dostępu: 17.08.2017).

${ }^{14}$ inkubatorkultury.szczecin.pl/o-nas/ (data dostępu: 10.08.2017). 
- wsparcie merytoryczne poprzez organizację warsztatów, konsultacji i spotkań sieciujących;

- wsparcie w zakresie pozyskiwania finansowania na działania;

- wsparcie w zakresie promocji i budowy wizerunku organizacji.

Tym samym młode organizacje, osoby z pomysłami na działanie w sferze kultury, animatorzy czy grupy nieformalne mogą liczyć na wsparcie: infrastrukturalne, marketingowe oraz doradcze. Niemniej jednak, by odpowiednie osoby z grupy docelowej otrzymały informacje o kierowanej do nich ofercie, istotne jest prowadzenie szerokich działań promocyjnych. W związku z tym przykład Szczecińskiego Inkubatora Kultury został wybrany w celu opracowania studium przypadku w zakresie wykorzystania modelu ZMOT.

$\mathrm{Na}$ wstępnym etapie analizy stwierdzono, iż INKU zatrudnia wskazaną osobę odpowiedzialną za dbałość o informacje na temat podmiotu znajdujące się w internecie, na różnego rodzaju platformach: na przykład na stronie www, ale i w mediach społecznościowych, na forach, portalach regionalnych i branżowych, co więcej osoba ta jest odpowiedzialna za opracowywanie treści oraz jej aktualizację. Pracownik ten nie zajmuje się bezpośrednio wyznaczeniem punktów styku podmiotu oraz klientów, ponieważ działania te realizują pozostali pracownicy podmiotu, w tym odpowiedzialni za strategię rozwoju organizacji, a przy okazji analizują oni również, skąd klienci podmiotu gromadzą o INKU informacje, jakich urządzeń (np. mobilnych) używają oraz z jakich kanałów komunikacji korzystają najczęściej.

Szczeciński Inkubator Kultury jako główne kanały komunikacji wybrał: stronę internetową, profil na portalu Facebook oraz Instagram. Publikowane są na tam na bieżąco informacje o prowadzonych akcjach kierowanych również do społeczności lokalnej, jak na przykład Wakacje w INKU, Warsztat w INKU, Kultura w INKU, Miniporadnik, Dobre praktyki, INKU czyta, Wolontariat jest super oraz wiele innych. Dodatkowo, by wzmocnić możliwości przekazu, Szczeciński Inkubator Kultury działa w sieci partnerstw organizacji kultury: Northern Dimension Partnership on Culture.

Na podstawie przeprowadzonej analizy sporządzono model ZMOT dla badanej organizacji, który został przedstawiony na rysunku 2.

Obecnie odbiorca oferty podmiotów kultury ma możliwość ciągłego poszerzania kontaktów z kulturą za pośrednictwem internetu, porównywania i weryfikowania, zanim podejmie decyzję o wyborze. Na decyzję tę w znaczącym stopniu wpływa to, co na etapie zerowego momentu prawdy potencjalny klient usłyszy, zobaczy czy też przeczyta. Zerowego momentu prawdy nie tworzą jedynie treści opracowywane przez dany podmiot, ale również opinie korzystających z danych usług. W znaczącej mierze to właśnie ich zdanie buduje konkretne komunikaty, którym ufają później pozostali potencjalni klienci. Tym samym w analizowanej organizacji ważne jest również, by poza oddelegowaniem właściwego pracownika do działań związanych ze ZMOT, zwracać baczną uwagę na wrażenia klientów 
INKU z przebywania w organizacji, pracy w biurach organizacji, odczucia towarzyszące udziałowi w warsztatach, imprezach kulturalnych oraz akcjach doradczych.

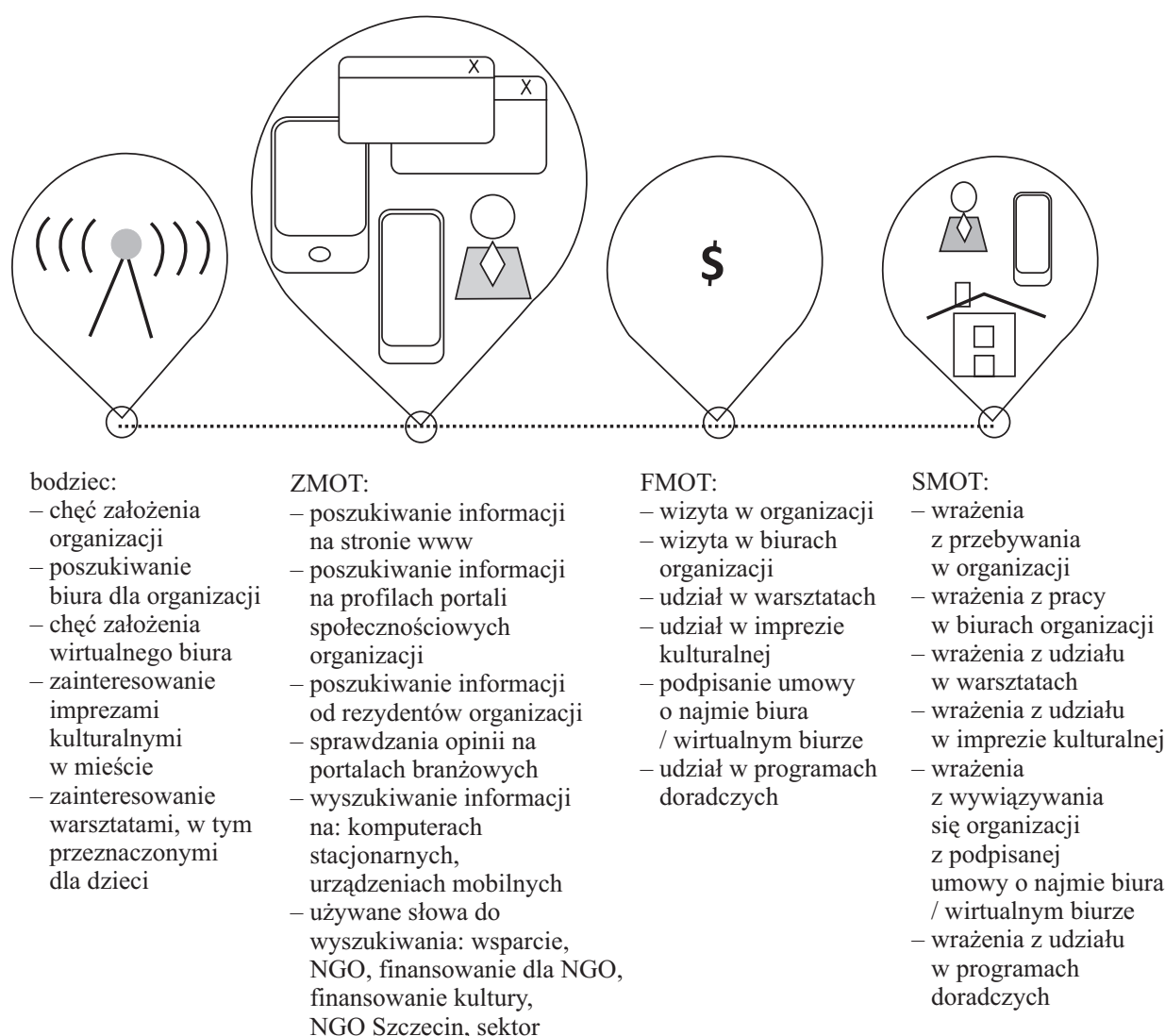

NGO Szczecin, sektor

kreatywny Szczecin

Rysunek 2. Model zerowego momentu prawdy - ZMOT opracowany na podstawie analizy Szczecińskiego Inkubatora Kultury

Źródło: opracowanie własne na podstawie: https://www.thinkwithgoogle.com/marketing-resources/micro-moments/zero-moment-truth/ (data dostępu: 15.08.2017).

\section{Wnioski}

Model ZMOT w podmiotach kultury może być stosunkowo łatwo aplikowany. Jego wdrożenie nie wymaga szczególnych nakładów finansowych, ale jedynie opracowania koncepcji komunikacji oraz jej całościowego wdrażania przez wskazany do tego personel. Istotne jest również, by przedstawiciele podmiotów kultury zdawali 
sobie sprawę, że nie tylko są specyficznymi organizacjami, ale także posiadają specyficzną ofertę, która wymaga przemyślanej promocji, gdyż bardzo często zgoda na skorzystanie z oferty wiąże się z jej konsumpcją. Jeśli oferta nie będzie odpowiadała klientowi, pozostawi to głęboki dysonans pozakupowy. Celem przeciwdziałania tego rodzaju negatywnym doświadczeniom należy mieć na uwadze, iż potencjalni klienci, którzy jeszcze nigdy danego podmiotu nie odwiedzili, nie korzystali z jego usług i tak będą mieli już na jego temat wyrobione zdanie. Dziać się tak będzie właśnie przez fakt pojawiania się zerowego momentu prawdy. Tym samym warto, by podmioty kultury czynnie zainteresowały się tym etapem na ścieżce współpracy z klientem.

\section{Bibliografia}

Buchnowska D., CRM strategia i technologia, Gdańsk 2006.

EC, Economy of Culture in Europe, DG Education and Culture, Bruksela 2006.

Koszarek M., Diagnoza sektora branż kreatywnych na obszarze Metropolii Gdańskiej, raport końcowy.

Mathews G., Supermarket kultury. Kultura globalna a tożsamość jednostki, Warszawa 2005.

OGC: Managing Successful Projects with PRINCE2, The Stationery Office, London 2009.

Podręcznik szkoleniowy dotyczący sektora kultury w Polsce dla wnioskodawców i partnerów programu Promowanie różnorodności kulturowej $i$ artystycznej $w$ ramach europejskiego dziedzictwa kulturowego finansowanego z funduszy EOG 2009-2014, Ministerstwo Kultury i Dziedzictwa Narodowego, Warszawa 2012.

\section{Źródła internetowe}

Etmanowicz A., Trzebański M., Martele B., Rekomendacje działań i kierunków wsparcia rozwoju przemysłów kreatywnych w województwie pomorskim, Toruń 2012, http://kreatywni.arp. gda.pl/plik,57,rekomendacje-dzialan-i-kierunkow-wsparcia-przemyslow-kreatywnych-w-wojewodztwie-pomorskim.pdf (data dostępu: 20.08.2017).

http://badania-w-kulturze.mik.krakow.pl/2012/02/22/sektor-kultury-ujecie-instytucjonalne-i-znaczenie-gospodarcze/ (data dostępu: 20.08.2017).

http://kreatywnapolska.pl/klasyfikacja-przemyslow-kreatywnych (data dostępu: 20.08.2017). https://www.thinkwithgoogle.com/marketing-resources/micro-moments/zero-moment-truth/ (data dostępu: 17.08.2017).

https://www.thinkwithgoogle.com/marketing-resources/micro-moments/zero-moment-truth/ (data dostępu: 15.08.2017).

inkubatorkultury.szczecin.pl/o-nas/ (data dostępu: 10.08.2017).

Mackiewicz M., Machorowska B., Śliwka A., Analiza potrzeb i rozwoju sektorów kreatywnych raport końcowy, Warszawa 2009, http://www.mg.gov.pl/files/upload/10147/Analiza\%20 potrzeb\%20i\%20rozwoju\%20przemyslow\%20kreatywnych.pdf (data dostępu: 20.08.2017). 